\title{
Effects of Visual, Verbal, Visual + Verbal Feedback on Learning of Dribbling and Lay-up Skill
}

\author{
Yasin Akinci ${ }^{1}$ and Sadettin Kirazci ${ }^{1}$ \\ 'Middle East Technical University, Faculty of Education, Physical Education and Sports Department, Ankara, Turkey
}

\begin{abstract}
The purpose of this study is to examine how different feedback conditions affect learning skills. Two-task dribbling, continuous skill, and lay-up discrete skill of basketball were selected, and participants were randomly grouped and assigned to verbal, visual + verbal, and visual feedback groups. Two experts evaluated the performances of the participants. First, a pre-test was applied to form the groups, then a day later subjects performed both task 15 times ( 5 trials, 3 sets) and received feedback after every 5 trials for three consecutive days; 72 hours later, a retention test was applied to test learning. A $3 \times 2$ (Group $\times$ Condition) ANOVA was used to calculate the differences between the groups in the pre-test and post-test conditions. The results indicated no significant difference between the groups for the two skills in the pre-test, but the post-test results indicated significant difference among the verbal to visual + verbal group, visual to visual + verbal group and verbal and visual group. The total difference scores of the groups were also significant; the visual + verbal condition indicated the greatest improvement, whereas the visual condition indicated the least improvement in skills. The study indicated that the verbal feedback for novice group caused better improvement and retention of the dribbling and lay-up basketball skills compared to the visual feedback group.
\end{abstract}

Keywords: skill learning, basketball, videotape feedback, verbal feedback

\section{Introduction}

Coaches, physical education teachers, trainers, and athletes are seeking methods to facilitate skills learning and performance development. Motor learning specialists are also interested in the same topic with the mechanisms that affect performance and learning. Feedback is regarded as an essential part of this teaching process (Rink, 2002). Feedback from an external source that influences performance is called "augmented feedback", which has motivational and informational functions (Coker et al., 2006; Smith, 2006). The motor learning field has been interested in the informational function of feedback, which indicates the role of providing knowledge about the student's performance concerning the task target. In this context, researchers have indicated methodological subjects, for example, the frequency, timing and accuracy of feedback (Salmoni, Schmidt, \& Walter, 1984; Williams, \& Hodges,
2004; Schmidt \& Lee, 2005). The way in which the feedback was used depends on the nature of the task and learner for reducing the feedback dependency. To explain the dependency-producing role of feedback, researchers presented the guidance hypothesis, which states that feedback is a mean to guide performers' actions with a both positive and negative "side effects" (Salmoni et al., 1984; Schmidt, 1991; Schmidt \& Wrisberg, 2000). Learners can correct errors and develop consequent trials performance by using knowledge about the results of a movement. Using frequent augmented feedback is also because of over-reliance on the guiding properties of the feedback; it thus plays a critical role between trial information processing involving coding storage and retrieval operations that is important for learning dimension (Bjork, 1988; Schmidt \& Lee, 1999; Schmidt \& Wrisberg 2000).

According to Bandura (1997), motor skills are also learned

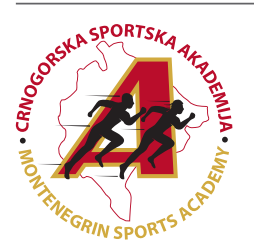

Correspondence:

Y. Akinci

Middle East Technical University, Faculty of Education, Physical Education and Sports Department, 06800 Ankara, Turkey,

E-mail: yasakinci@hotmail.com 
through observation. Bandura suggests that when a learner views a performer, s/he will keep essential knowledge about skill than it is used as a cognitive illustration, for trying to replicate the skill. Learning through observation was the concern of feedback studies, which were videotape and computer analysis, and were frequently used as a source of information both in education and sport setting. Videotape feedback (VTFB), contains high-intensity information, provides the clarity and time needed for useful instructions in the realization of the successful movement learning process (Hubwieser, 2007; Niegemann et al., 2013). With this, VTFB allows for the explanation of movements or partial elements that may be difficult to identify at first (Schön \& Ebner, 2013). It is supposed that viewing learners' motion with VTFB stimulated corrections and consequently improves performance. In the cognitive perspective, a person crosschecks on the video display to a criterion, detect errors and build corrections on the following performances. In general, researchers (Miller, \& Gabbard, 1988; Haguenauer et al., 2005; Jennings, Reaburn, \& Rynne, 2013) suggest that using video as a form of performance feedback can be a beneficial tool to improve motor skill learning and performance (Razali, Suwarganda, \& Zawaki 2012; Barzouka, Sotiropoulos, \& Kioumourtzoglou, 2015; Giannousi, Mountaki, \& Kioumourtzoglou, 2017). However, research regarding VTFB is inconsistent (Tzetzis et al., 1999; Ram \& McCullagh, 2003; Clark \& Ste-Marie, 2007), and the impact of this seems to be related to the characteristics of the learners, with increased benefits from those more skilled in the task, or more practice with VTFB. In brief, learners gain information about the performance or experience seeing VTFB; they are adjusted at selecting information, error detection, and correction, and using this information (Darden, 1999).

The level of performer, type of skill or movement, instructor-provided feedback, and frequency of viewing and other variables should be considered when using VTFB to increase motor skill learning.

Therefore, the purpose of this study was to examine the effect of investigate the differences in the learning of two fundamental skills of basketball (dribbling and lay-up skills) with verbal, visual + verbal, and visual feedback and verbal feedback condition, visual + verbal, feedback condition and visual feedback condition processing from the pre to post-test phases.

Accordingly, it was hypothesized that there was significant difference both in the scores of the three feedback conditions in the post-test results indicating learning effect and in the total difference scores of the feedback groups indicating an improvement from pre to post-test.

\section{Methods}

Subjects

Twenty-four male and twenty-one female third-grade primary school students with no prior experience in basketball were selected as subjects of the study. The average age of the students was $M=9.2 \pm 0.2$, were randomly assigned to three feedback groups which are visual feedback, verbal feedback, visual + verbal feedback group.

Permission to conduct the study was received both from Middle East Technical University Ethics Committee. The researcher highlighted that it was not compulsory to take part and that all information gathered would be treated as confidential. Participants were given an informed consent form to be signed by their parents.

\section{Apparatus and Task}

The experts used a basketball dribbling and lay-up skill evaluation checklist that had an "A" class basketball-coaching certificate. The goal of the dribbling skill was to dribble the ball around cones 10 metres apart with the dominant hand using the correct technique. The goal of the lay-up task was to perform the correct lay-up technique from 7 metres from the right or left side of the court according to preference.

Before the subjects had started to perform the task, the instructor demonstrated the correct technique and explained the essential parts of the skills. Experts evaluated the participants while they were performing the skills and subjects received feedbacks according to the expert's evaluation. The instructor verbally gave the performer the most important four-feedback title from the skill evaluation checklist.

The reliability and validity of the checklist were done by Çamur (2001). The study was done in a FIBA dimensions basketball court and rim heights. Participants performed both tasks with No: 5-size basketball ball.

A digital camera connected to a $55-\mathrm{cm}$ screen TV was used to recorded and watched visual and visual + verbal feedback group subject's performance. Both two experts and cameraman had the full vision of participants' performance during the whole experiment.

\section{Procedure and Design}

In this study, three groups receiving verbal, visual + verbal, and visual knowledge of performance feedback practised the lay-up and dribbling skill of basketball. The study was conducted on eight days for all three-feedback groups. The schematic design of the study was given in Table 1 .

On the first day, participants performed two tasks with five trials as pre-test and experts evaluated them with three scores for tasks and sub tittles of tasks. Subjects were assigned to the feedback groups randomly. On the second day, participants were on a 24-hour rest interval. On the third, fourth, and fifth days, the subjects performed the training (acquisition).

In the acquisition phase, subjects were first separated into three groups, with five participants for every feedback group. The first five subjects performed the task five times then received feedback. While the first five subjects were receiving the feedback, the second five started to the task. When the first five finished to receiving feedback, waited for a little for second five students to finish the task and went to receive feedback. This process applied during the three-acquisition day.

After 72 hours, a retention test was applied on the eightday. Subjects completed a total of 15 trials for retention posttest. During the retention test, no subjects received any feedback.

\section{Statistical Design}

To test the hypothesis and to calculate the group differences in pre-test and post-test, data were analysed with a $3 \times$ 2 (Group $\times$ Condition) analysis of variance (ANOVA). A significance level of $\mathrm{p}<.05$ was set for all statistical tests. Tukey's honestly significant difference (HSD) procedure was adopted for all follow-up comparisons when appropriate.

\section{Reliability of experts}

Before the data collection of study, Covariance matrix and correlation matrix was used for the reliability of the experts over 15 subjects independently. The estimated reliability of 
Table 1. Overall Study Design

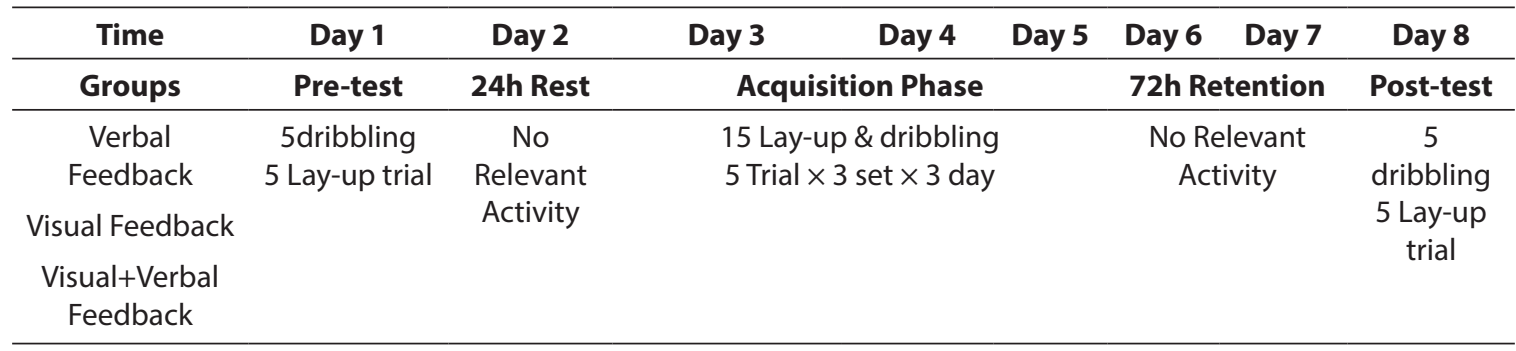

Legend: $\mathrm{N}=15$ for the three groups

the scale was 0.79 , and the unbiased estimate of reliability was 0.78 . Both the R-values are higher than 0.70 , so these results indicate that the experts were highly reliable between and within.

\section{Results}

\section{Preliminary analyses}

The mean and standard deviation of three feedback groups on dribbling and lay-up skill of students are shown in Table 2. The pre-test analysis aimed to compare the baseline scores for each feedback group before training intervention. Thus, one-way ANOVA was used to analyse to test the difference in visual, verbal, and visual +verbal feedback condition on the pre-test values. The results revealed that there were no statistically significant differences between the three feedback groups in the pre-test in dribbling performance scores $\mathrm{F}(2.42)=0.357$ $\mathrm{p}<0.05$, nor in the lay-up performance scores $\mathrm{F}(2.42)=0.195$ $\mathrm{p}<0.05$.

\section{Main analyses}

The ANOVA results for the dribbling post-test revealed a significant main effect for three feedback conditions, $\mathrm{F}(2.42)=14.01 \mathrm{p}<0.05$, and for the lay-up $\mathrm{F}(2.42)=20.66$ $\mathrm{p}<0.05$. Tukey's HSD follow up for the dribbling performance revealed statistically significant differences among the scores of verbal condition $(M=690.66 ; S D=207.44)$ to both visual conditions $(\mathrm{M}=559.33 ; \mathrm{SD}=156.94)$, and visual + verbal condition ( $\mathrm{M}=875.06 ; \mathrm{SD}=114.57)$. Tukey's HSD follow up for the layup performance revealed statistically significant differences among the scores of verbal condition $(M=851.66 ; S D=258.11)$ to both visual conditions $(\mathrm{M}=710.01 ; \mathrm{SD}=210.01)$, and visual + verbal condition $(\mathrm{M}=1231.01 ; \mathrm{SD}=217$.

Table 2. Descriptive Statistics for Feedback Groups for Dribbling and Lay-up Tasks

\begin{tabular}{lccccc}
\hline \multirow{2}{*}{ Groups } & & \multicolumn{2}{c}{ Dribbling } & \multicolumn{2}{c}{ Lay-up } \\
& & Pre-test & Post-test & Pre-test & Post-test \\
\hline \multirow{2}{*}{ Verbal Feedback } & M & 420.33 & 690.66 & 496.33 & 851.66 \\
& SD & 192.57 & 207.44 & 223.62 & 258.11 \\
Visual Feedback & M & 381.33 & 559.33 & 474.66 & 710.01 \\
& SD & 156.49 & 156.94 & 208.49 & 210.01 \\
Visual + Verbal Feedback & M & 410.33 & 875.06 & 547.33 & 1231.01 \\
& SD & 181.45 & 114.57 & 286.34 & 217.45 \\
\hline
\end{tabular}

Legend: $\mathrm{M}$ - mean score; SD - standard deviation.

Figure 1 shows the dribbling mean scores of the three feedback conditions from pre-test to post-test.

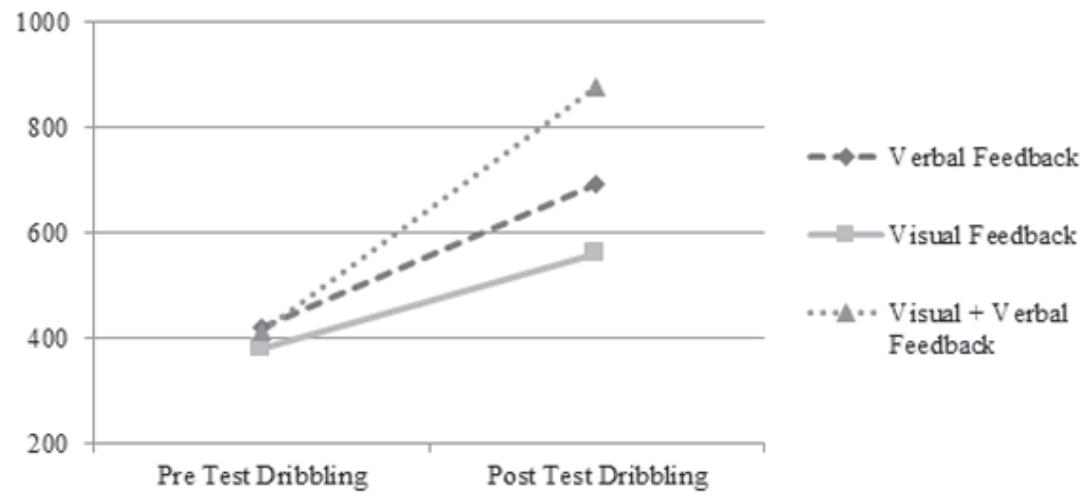

Figure 1. Dribbling Mean Scores of the groups During Pre-test and Post-test

The ANOVA results for the total difference revealed a statistically significant main effect for the conditions of dribbling performance, $\mathrm{F}(2.42)=46.18 \mathrm{p}<0.05$ and lay-up performance, $\mathrm{F}(2.42)=100.47 \mathrm{p}<0.05$. Tukey's HSD follow up for dribbling performance revealed statistically significant differences among the scores of verbal con- 
dition $(\mathrm{M}=270.33 \mathrm{SD}=54.72)$ to both visual conditions $(\mathrm{M}=178.00 ; \mathrm{SD}=36.73)$, and visual + verbal condition $(\mathrm{M}=464.73 ; \mathrm{SD}=128.57)$. These results showed that visual + verbal feedback condition has the largest improvement test scores, but the visual condition has the least improvement in dribbling skill.

The lay up mean scores of the three feedback conditions from pre-test to post-test were shown in Figure 2.

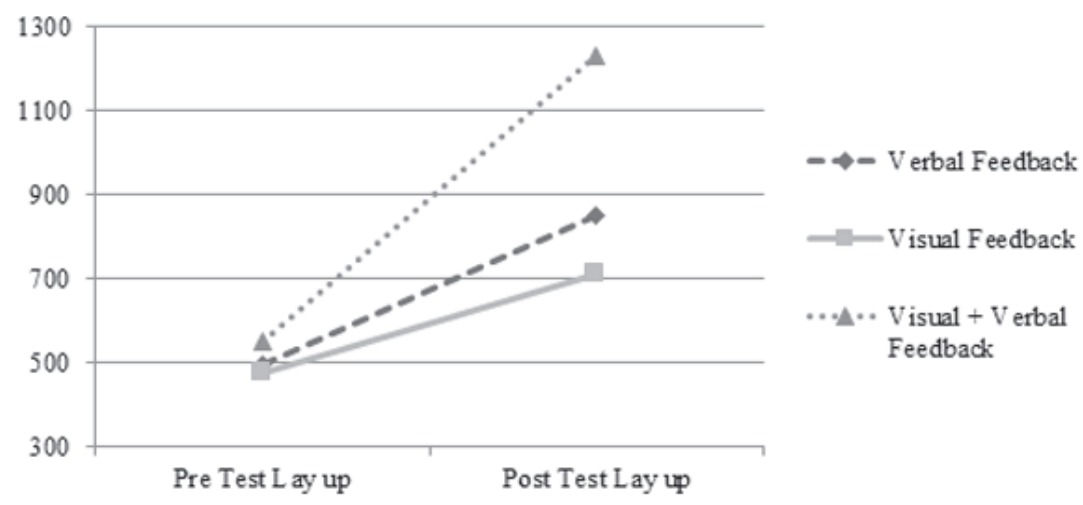

Figure 2. Lay-up Mean Scores of the groups During Pre-test and Post-test

Tukey's HSD follow up for lay-up performance revealed statistically significant differences among the scores of verbal condition $(\mathrm{M}=355.33$; $\mathrm{SD}=66.12)$ to both visual conditions $(M=235.33 ; \mathrm{SD}=67.94)$, and visual + verbal condition $(M=683.66 ; S D=123.03)$. These results showed that the vi- sual + verbal feedback condition has the most substantial improvement in test scores, but the visual condition has the least improvement in lay-up skill. Figure 3 shows the total difference scores of the three feedback conditions as improvement scores.

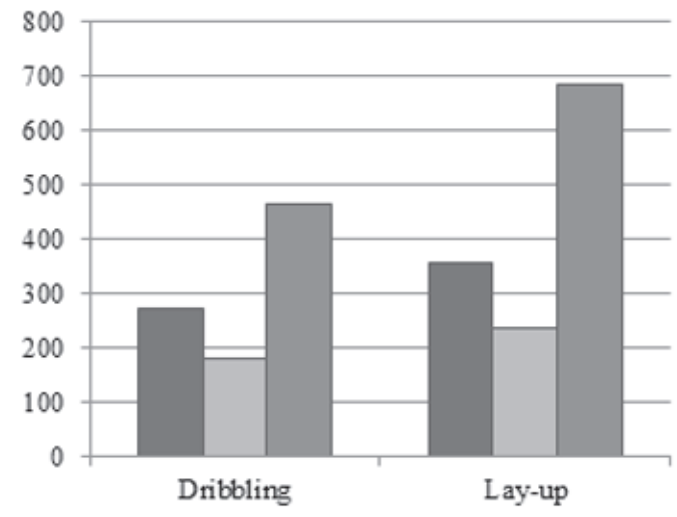

QV erbal Feedback

$\square$ Visual Feedback

aVisual+V ervbal Feedback

Figure 3. Dribbling and Lay-up Total Difference Scores of the Three Feedback Groups

\section{Discussion}

This study examined the effect of different feedback conditions on the dribbling and lay-up skills in basketball. The results of the study revealed that there was a significant difference in the post-test scores of verbal, visual + verbal, and visual feedback groups. This difference was caused by the verbal feedback group and the visual + verbal feedback group over the visual feedback group.

Baundry, Leroy, and Chollet (2006) examined the effect of visual feedback to the learning double leg circle on the pommel horse of gymnastic skills for 16 subjects at the age of 14.3 with a minimum of six years of experience. The subjects were set in groups of eight, and they practised ten sequences of six circles for four days. The results demonstrated that subjects in the visual group who had the chance to watch their performance exhibited considerable improvement. The results indicate that visual feedback enhances the error detection capability of the learner and analysis of the specific parts of the intricate movement patterns.

Zetou, Tzetzis, Vernadakis, and Kioumourtzoglou (2002) examined the effect of different feedback conditions on the performance and learning of serving and setting skills of volleyball for 116 elementary school children at the average age of 11.7. Subjects were randomly assigned to an expert modelling video feedback group and a self-modelling video feedback group. After the eight-week intervention, subjects in both groups improved their serving and setting skills but more in expert modelling video feedback group on acquisition and retention.

In conclusion, VTFB was appropriate for the tasks that serving and setting were simple, and the cognitive levels of the learners permit understanding the specific aspects of the skills. In the study Aiken, Fairbrother, and Post (2012), basketball set shot technique was investigated. Twenty-eight female subjects at the mean age of 26.4 were randomly assigned to a self-controlled video feedback group and yoked video feedback group. The results revealed that the self-controlled video feedback 
group had significantly higher results during the transfer and acquisition phase. The amount and the type of feedback depend mainly on the cognitive level of learner and the characteristics of the skill. In this study, adults have a higher understanding, error detection, and error correction capability; therefore, VTFB has been more effective in learning.

In contrast, VTFB is not always beneficial. Ineffective use of VTFB for learning has been attributed to such variables as the level of performer, type of skill or movement, the instructor provided feedback, and frequency of viewing. These and the other variables should be considered when using VTFB to improve the learning of motor skills. In the studies of Whiting (1989) and Rusell (1993), VTFB was not as useful as the studies mentioned above.

Jennings et al. (2013) examined the effectiveness of videotape feedback on the cycling standing start performance of novice track cyclists. Nineteen subjects at the average age of 13.6 were assigned to traditional verbal feedback intervention group and video self-modelling feedback intervention group. The results failed to show a significant difference or interaction between the two groups on the performance. The evidence indicates that VTFB depends on learning process especially when the task was complex and learners were young or novice, seeing one's performance on video does not automatically accomplish the goals of feedback, it takes time and repetition for visual feedback to promote valuable cognitive effort.

Rusell (1993) examined the effect of traditional and videotape feedback method on the learning of hockey skills to the students at the age of 12 . Subjects were separated into two groups of 15 students each. The results of the study demonstrated that there were significant differences between videotape and traditional feedback groups. The videotape feedback group had higher scores than traditional groups.

Boyce, Markos, Jenkins, and Loftus (1996) determined that teacher-provided verbal feedback was often the most effective for third graders, but for fifth graders VTFB was more effective than teacher-provided verbal feedback or peer feedback. Hebert, Landin and Menickelli (1998) also suggest that beginners and younger students might be more dependent on feedback and less able to process and use VTFB.

The ability to detect critical elements of the movement is vital for the proceeding "associative" stage of learning. VTFB must be supported via verbal and written clues to keep attention to those cues for better performance and learning. In this stage, learners may lose their motivation by focusing on the entire movement or result of the movement. In this case, instructors may quit VTFB, but the lowered motivation typifies early stages of learning, is temporary with appropriate experiences. The more successful they are in identifying and correcting errors, the higher the motivation and enthusiasm for students to use VTFB.

The hypotheses of the study were supported by the liter-

\section{Acknowledgements}

There are no acknowledgements.

\section{Conflict of Interest}

The authors declare that there are no conflicts of interest.

Received: 07 October 2019| Accepted: 30 November 2019| Published: 01 February 2020

\section{References}

Aiken, C.A., Fairbrother, J.T., \& Post, P.G. (2012). The effects of self-controlled video feedback on the learning of the basketball set shot. Frontiers in ature. The movement pattern scores of visual + verbal feedback scores were higher than the verbal feedback group, and verbal feedback groups scores were higher than the modelling feedback group. The reason for the low scores in visual feedback group is that; VTFB requires cognitive effort to comprehension (especially for the children). The study supported the second hypothesis that total difference scores of visual + verbal feedback scores were higher than verbal feedback group, and verbal feedback groups scores were higher than the visual feedback for both the dribbling and the lay-up tasks. Also, the literature, which was in agreement with this study, indicated that when the VTFB combined with the verbal cues or verbal feedback, the improvement in skill learning and performance became greater. Researches in these areas suggest that cognitive processes play an essential role during the early stages of skill acquisition.

In contrast, the learning of the dribbling is lower than the learning of the lay-up skill. The source of this difference is the nature of the skills. As is known, dribbling is a continuous skill and lay-up is a discreet skill. On the learning of lay-up skill, feedback is more concrete; for example, start with right foot, head and eyes looking at basket, land on two feet, etc. However, on the learning of dribbling skill, the feedback is more flexible, for example, knees make a slight forward angle, keep the centre of gravity in hip, push the ball through the floor in harmony starting from elbow to wrist, etc. For that reason, children showed considerable improvement in lay-up (discreet) skill.

The notion that motor skill learning occurs in stages is popular in pedagogical and motor-learning literature (Magill, 2001; Rink, 2002; Utley, Andrea \& Astill 2018). Generally, the literature reveals that learners need to pass through "cognitive,", "associative", and "autonomous" stages of motor learning to exhibit more consistency, show good ability to detect and correct errors, and well-defined motor programs (Magill, 1998). The transitions between the stages of the learning process need continuum and shifts gradually. The similar approach should be considered in the application of VTFB, and the learners' stage should be assessed carefully for enhancing motor skill learning. The particular elements of the movements, covers the instructional goals, should be given in the form of VTFB consistently immediate after practice until attaining mastery in specific sport skill.

Based on the findings of the study, the following recommendation might be considered in future studies. Firstly, verbal feedback for novice learners seems to be better than visual feedback. Secondly, VTFB and verbal feedback should be used together to get better learning and performance results. Thirdly, a control group can be added to the design of the study for assessing the practice only effect. Finally, visual-only feedback to an expert group can be given to assess the difference between the novice and the expert group.

psychology, 3, 338

Bandura, A. (1997). Self-efficacy: The exercise of control. Macmillan.

Barzouka, K., Sotiropoulos, K., \& Kioumourtzoglou, E. (2015). The effect of feedback through an expert model observation on performance and learning the pass skill in volleyball and motivation. Journal of Physical Education \& Sport, 15(3), 407-416.

Baundry, L., Leroy, D., \& Chollet, D. (2006). The effect of combined self- and expert-modelling on the performance of the double leg circle on the pommel horse. Journal of Sports Sciences, 24(19), 1055-1063. https://doi. org/10.1080/02640410500432243

Bjork, R.A. (1988). Retrieval practice and the maintenance of knowledge. Practical aspects of memory: Current research and issues, 1, 396-401. 
Boyce, B.A., Markos, N.J., Jenkins, D.W., \& Loftus, J.R. (1996). How should feedback be delivered? Journal of Physical Education, Recreation \& Dance, 67(1), 18-22.

Clark, S.E., \& Ste-Marie, D.M. (2007). The impact of self-as-a-model interventions on children's self-regulation of learning and swimming performance. Journal of sports sciences, 25(5), 577-586.

Coker, C.A., Fischman, M.G., \& Oxendine, J.B. (2006). Motor skill learning for effective coaching and performance. In J. M. Williams (Ed.), Applied sport psychology: Personal growth to peak performance (5th ed., pp. 18-40). New York: McGraw-Hill Companies.

Çamur, H. (2001). Basketbolda dribling ve turnike becerilerinin öğretiminde canlı, videolu ve canlı+ videolu dönütün başarıya etkisi. Yayımlanmamış Yüksek Lisans Tezi). Ankara: Hacettepe Üniversitesi.

Darden, G.F. (1999). Videotape feedback for student learning and performance: A learning-stages approach. Journal of Physical Education Recreation \& Dance, 70(9), 40-45

Giannousi, M., Mountaki, F., \& Kioumourtzoglou, E. (2017). The effects of verbal and visual feedback on performance and learning freestyle swimming in novice swimmers. Kinesiology: International journal of fundamental and applied kinesiology, 49(1), 65-73.

Haguenauer, M., Fargier, P., Legreneur, P., Dufour, A.B., Cogerino, G., Begon, M., \& Monteil, K.M. (2005). Short-term effects of using verba instructions and demonstration at the beginning of learning a complex skill in figure skating. Perceptual and motor skills, 100(1), 179-191.

Hubwieser, P. (2007). Didaktik der Informatik: Grundlagen, Konzepte, Beispiele. Springer-Verlag.

Jennings, C.T., Reaburn, P., \& Rynne, S.B. (2013). The effect of a self-modelling video intervention on motor skill acquisition and retention of a novice track cyclist's standing start performance. International Journal of Sports Science \& Coaching, 8(3), 467-480.

Magill, R.A. (1998). Knowledge is more than we can talk about: Implicit learning in motor skill acquisition. Research Quarterly for Exercise and Sport, 69(2), 104-110.

Magill, R.A. (2001). Augmented feedback in motor skill acquisition. Handbook of sport psychology, 86-114.

Miller, G., \& Gabbard, C. (1988). Effects of visual aids on acquisition of selected tennis skills. Perceptual and motor skills, 67(2), 603-606.

Niegemann, H.M., Hessel, S., Hochscheid-Mauel, D., Aslanski, K., Deimann, M., \& Kreuzberger, G. (2013). Kompendium E-learning. Springer-Verlag

Ram, N., \& McCullagh, P. (2003). Self-modeling: Influence on psychological responses and physical performance. The Sport Psychologist, 17(2), 220-
241.

Razali, R., Suwarganda, E., \& Zawaki, I. (2012). The effect of direct video feedback on performance of tennis serve. In ISBS-Conference Proceedings (241-244), Melbourne.

Rink, J.E. (2002). Teaching physical education for learning (4th ed.). New York: McGraw-Hill.

Russell, D. (1991). The effects of prototypic examples and video replay on adolescent girls' acquisition of basic field hockey skills. Doctoral dissertation, University of British Columbia.

Salmoni, A.W., Schmidt, R.A., \& Walter, C.B. (1984). Knowledge of results and motor learning: a review and critical reappraisal. Psychological bulletin, 95(3), 355.

Schmidt, R.A. (1991). Frequent augmented feedback can degrade learning: Evidence and interpretations. In Tutorials in motor neuroscience (59-75). Springer, Dordrecht.

Schmidt, R.A., \& Wrisberg, C.A. (2000). Motor learning and performance a problem-based learning approach (2nd ed.). Human Kinetics, Champaign, IL.

Schmidt, R.A., \& Lee, T.D. (1999). Motor control and learning: A behavioral emphasis (3rd ed.). Human Kinetics, Champaign, IL.

Schmidt, R.A., \& Lee, T.D. (2005). Motor control and learning: A behavioral emphasis (4th ed.). Champaign, IL: Human Kinetics.

Schön, S., \& Ebner, M. (2013). Gute Lernvideos:... so gelingen Web-Videos zum Lernen. BoD-Books on Demand.

Smith, R.E. (2006). Positive reinforcement, performance feedback, and performance enhancement. In J. M. Williams (Ed.), Applied sport psychology: Personal growth to peak performance (5th ed., 41-57). New York: McGraw-Hill Companies.

Tzetzis, G., Mantis, K., Zachopoulou, E., \& Kioumourtzoglou, E. (1999). The effect of modeling and verbal feedback on skill learning. Journal of Human Movement Studies, 36(3), 137-141.

Utley, A. (2018). Motor Control, Learning and Development: Instant Notes. Routledge.

Whiting, H.J. (1988). Imitation and the learning of complex cyclical actions. In Advances in psychology, 50, 381-401. North-Holland.

Williams, A.M., \& Hodges, N.J. (2004). Skill acquisition in sport: Research, theory and practice. Routledge.

Zetou, E., Tzetzis, G., Vernadakis, N., \& Kioumourtzoglou, E. (2002). Modeling in learning two volleyball skills. Perceptual and motor skills, 94(3 suppl), 1131-1142. 